\title{
Bilateral Genu Valgum in an Adolescent with Primary Hyperparathyroidism: A Case Report and Review of Literature
}

\author{
Siow Ping Lee, ${ }^{1}$ Shu Teng Chai, ${ }^{1}$ Leh Teng Loh, ${ }^{2}$ Norhaliza Mohd $\mathrm{Ali}^{1}$ \\ ${ }^{1}$ Department of Medicine, Hospital Sultanah Aminah, Johor, Malaysia \\ ${ }^{2}$ Gleneagles Medini, Johor, Malaysia
}

\begin{abstract}
Primary hyperparathyroidism in children and adolescents is rare and often symptomatic at presentation. A 15-year-old boy presented with bilateral genu valgum for two years. Biochemical results were consistent with primary hyperparathyroidism. Calcium levels normalized two months after removal of a left inferior parathyroid adenoma.
\end{abstract}

Key words: primary hyperparathyroidism, adolescent, genu valgum, parathyroid neoplasms

\section{INTRODUCTION}

Primary hyperparathyroidism (PHPT) is a disorder of bone and mineral metabolism caused by autonomous secretion of parathyroid hormone (PTH). It is mainly seen in adults between 50 and 60 years of age, with an annual incidence of 30 per 100,000 and a lifetime prevalence of one per 1,000. The female to male ratio is approximately $3: 1{ }^{1}$ On the other hand, PHPT in children and adolescents is rare, with a prevalence of two to five cases per 100,000 and no apparent sex predilection. ${ }^{1,2}$ In contrast to adults who are often asymptomatic and commonly recognized during routine biochemical screening, children and adolescents with PHPT are mostly clinically symptomatic with endorgan damage. These include skeletal abnormalities and/or nephrolithiasis at presentation. ${ }^{2}$

Genu valgum is an unusual manifestation of PHPT in children and adolescents. To date, there is a limited number of published reports describing such presentation. We report a young patient who had bilateral genu valgum as a result of a parathyroid adenoma.

\section{CASE}

A 15-year-old boy presented in October 2018 with bilateral knock-knee for two years. He had an uneventful antenatal history and normal developmental milestones. He did not have any knee pain, swelling or stiffness. He had no history of injury, fracture or infection to his knees or legs. None of his family members had disorders related to multiple endocrine neoplasia type 1 (MEN 1) or type 2A (MEN 2A), hyperparathyroidism-jaw tumor (HPT-JT) syndrome or familial isolated hyperparathyroidism (FIHPT).
Physical examination revealed short stature (below $5^{\text {th }}$ percentile) and bilateral genu valgum (Figure 1). There were nobony deformities including those typical of rickets. Hehad no polydactyly, joint laxity or lumbar kyphosis to suggest skeletal dysplasia. The knee joints were not swollen, tender or warm. Laboratory evaluation showed hypophosphatemia and elevated levels of calcium, alkaline phosphatase and intact parathyroid hormone (iPTH), consistent with the diagnosis of primary hyperparathyroidism (Table 1). Neck ultrasonography revealed a well-defined hypoechoic lesion measuring $1.2 \times 1.5 \times 2.7 \mathrm{~cm}$ at the inferior pole of left thyroid lobe. Kidney and liver function tests were normal. Unfortunately, serum vitamin D, urinary calcium, kidney ultrasonography and bone mineral density scan were not performed in this case.

He subsequently underwent left inferior parathyroidectomy in December 2018. Histopathologic examination of the resected parathyroid gland confirmed a parathyroid adenoma. His immediate postoperative serum calcium was $1.9 \mathrm{mmol} / \mathrm{L}$, for which he received oral calcium and calcitriol for a month. His calcium levels normalized two months after surgery (Table 1). Meanwhile, corrective osteotomy is currently being contemplated by the pediatric orthopedic surgery team.

\section{DISCUSSION}

Our adolescent patient presented with bilateral genu valgum as a result of excessive parathyroid hormone secretion from a parathyroid adenoma. His age at presentation corresponds to those with a similar deformity described in literature (Table 2). Majority of reported cases presented during the adolescent period-between 11 to 17
ISSN 0857-1074 (Print) | eISSN 2308-118x (Online)

Printed in the Philippines

Copyright (C) 2020 by Lee et al.

Received: July 20, 2020. Accepted: September 21, 2020.

Published online first: November 29, 2020.

https://doi.org/10.15605/jafes.035.02.07
Corresponding author: Siow Ping Lee, $M D$

Physician and Endocrine Fellow

Endocrine Unit, Department of Medicine

Hospital Sultanah Aminah, Jalan Persiaran Abu Bakar Sultan

80100 Johor Bahru, Johor, Malaysia

Tel. No.: +6072257000

Fax No.: +6072242694

E-mail: patricia82@hotmail.my

ORCiD: https://orcid.org/0000-0003-0104-6978 
Table 1. Preoperative and postoperative biochemical profile

\begin{tabular}{lcccc}
\hline \multicolumn{1}{c}{ Parameters } & $\begin{array}{c}\text { Preoperation } \\
\text { (October 2018) }\end{array}$ & $\begin{array}{c}\text { Two months } \\
\text { post-operation } \\
\text { (February 2019) }\end{array}$ & $\begin{array}{c}\text { Six months } \\
\text { post-operation } \\
\text { (June 2019) }\end{array}$ & $\begin{array}{c}\text { Reference } \\
\text { range }\end{array}$ \\
\hline Corrrected calcium, mmol/L & 2.97 & 2.14 & 2.13 & $2.10-2.55$ \\
Phosphate, mmol/L & 1.03 & 1.64 & 1.3 & $1.45-2.10$ \\
Alkaline phosphatase, U/L & 1354 & 560 & 377 & $116-468$ \\
Intact PTHa, pmol/L & 154 & - & - & $1.5-7.6$ \\
Creatinine, $\mu \mathrm{mol} / \mathrm{L}$ & 33 & 55 & - & $50-77$ \\
\hline aPTH, parathyroid hormone & & & &
\end{tabular}

Table 2. Primary hyperparathyroidism presenting as genu valgum: A summary of case reports and case series from published literature

\begin{tabular}{|c|c|c|c|c|c|c|}
\hline Publication & Year & Age, yr & Gender & End-organ damage & Etiology & Outcome after parathyroidectomy \\
\hline McClure RD et $\mathrm{al}^{6}$ & 1945 & 14 & Female & Skeletal abnormalities & Left inferior parathyroid adenoma & $\begin{array}{l}\text { Biochemical normalization and } \\
\text { spontaneous correction of genu valgum }\end{array}$ \\
\hline Balch HE et $\mathrm{al}^{3}$ & 1953 & 21 & Female & Skeletal abnormalities & Left inferior parathyroid adenoma & $\begin{array}{l}\text { Hungry bone syndrome in immediate } \\
\text { post-operative period, followed } \\
\text { by biochemical normalization and } \\
\text { recalcification of demineralized bones }\end{array}$ \\
\hline Lloyd ${\mathrm{HM} \text { et } \mathrm{al}^{7}}^{7}$ & 1965 & 14 & Male & Skeletal abnormalities & Left inferior parathyroid adenoma & $\begin{array}{l}\text { Biochemical normalization and skeletal } \\
\text { improvement }\end{array}$ \\
\hline \multirow[t]{2}{*}{ Rapaport D et al ${ }^{4}$} & 1986 & 15 & Female & $\begin{array}{l}\text { Skeletal abnormalities, } \\
\text { nephrolithiasis }\end{array}$ & Right inferior parathyroid adenoma & Clinical and biochemical resolution \\
\hline & & 15 & Male & $\begin{array}{l}\text { Skeletal abnormalities, } \\
\text { nephrolithiasis }\end{array}$ & Right inferior parathyroid adenoma & Clinical and biochemical resolution \\
\hline Kauffmann $\mathrm{C}$ et $\mathrm{al}^{8}$ & 1993 & 13 & Female & Skeletal abnormalities & Left inferior parathyroid adenoma & $\begin{array}{l}\text { Biochemical normalization and } \\
\text { resolution of bone demineralization }\end{array}$ \\
\hline Menon PS et $\mathrm{al}^{9}$ & 1994 & 14 & Female & $\begin{array}{l}\text { Skeletal abnormalities, } \\
\text { nephrolithiasis }\end{array}$ & Left superior parathyroid adenoma & Normalization of calcium and phosphate \\
\hline Harman CR et al ${ }^{10}$ & 1999 & 14 & Female & Skeletal abnormalities & - & - \\
\hline Walczyk A et al ${ }^{11}$ & 2011 & 15 & Male & Skeletal abnormalities & Right inferior parathyroid adenoma & $\begin{array}{l}\text { Biochemical resolution and improvement } \\
\text { of } \mathrm{BMD}^{\mathrm{a}}\end{array}$ \\
\hline Dutta D et $a^{21}$ & 2013 & 12 & Female & Skeletal abnormalities & Right inferior parathyroid adenoma & Clinical and biochemical resolution \\
\hline Ratnasingam $\mathrm{J}$ et $\mathrm{al}^{12}$ & 2013 & 15 & Female & Skeletal abnormalities & Right parathyroid adenoma & Biochemical resolution \\
\hline \multirow[t]{2}{*}{ Ramkumar $\mathrm{S}$ et $\mathrm{al}^{13}$} & 2014 & 16 & Male & Skeletal abnormalities & Left inferior parathyroid adenoma & Biochemical resolution \\
\hline & & 13 & Male & Skeletal abnormalities & Right inferior parathyroid adenoma & Biochemical resolution \\
\hline Sharma S et al ${ }^{14}$ & 2016 & 15 & Female & Skeletal abnormalities & Left inferior parathyroid adenoma & Biochemical resolution \\
\hline Zil-E-Ali A et al ${ }^{15}$ & 2016 & 14 & Female & Skeletal abnormalities & Right inferior parathyroid adenoma & Biochemical resolution \\
\hline Arambewela $\mathrm{MH}$ et al ${ }^{16}$ & 2017 & 12 & Female & Skeletal abnormalities & Right inferior parathyroid adenoma & $\begin{array}{l}\text { Resolution of primary } \\
\text { hyperparathyroidism }\end{array}$ \\
\hline \multirow[t]{2}{*}{ Kamath SP et al ${ }^{17}$} & 2018 & 11 & Female & Skeletal abnormalities & Left superior parathyroid adenoma & Normalization of iPTH ${ }^{\mathrm{b}}$ \\
\hline & & 12 & Male & $\begin{array}{l}\text { Skeletal abnormalities, } \\
\text { nephrolithiasis }\end{array}$ & Left superior parathyroid adenoma & Normalization of iPTH ${ }^{\mathrm{b}}$ \\
\hline Khan KA et $\mathrm{al}^{22}$ & 2019 & 17 & Male & Skeletal abnormalities & Left inferior parathyroid adenoma & Biochemical resolution \\
\hline \multirow[t]{2}{*}{ Paruk IM et al ${ }^{18}$} & 2019 & 17 & Male & Skeletal abnormalities & Left inferior parathyroid adenoma & Clinical and biochemical resolution \\
\hline & & 13 & Male & Skeletal abnormalities & Right superior parathyroid adenoma & Clinical and biochemical resolution \\
\hline Rao KS et al ${ }^{19}$ & 2019 & 12 & Female & $\begin{array}{l}\text { Skeletal abnormalities, } \\
\text { nephrolithiasis }\end{array}$ & Right inferior parathyroid adenoma & $\begin{array}{l}\text { Hungry bone syndrome in immediate } \\
\text { post-operative period, long term } \\
\text { outcome not reported }\end{array}$ \\
\hline Yanrismet $\mathrm{Y}$ et $\mathrm{al}^{20}$ & 2019 & 13 & Male & Skeletal abnormalities & Right inferior parathyroid adenoma & $\begin{array}{l}\text { Hungry bone syndrome in immediate } \\
\text { post-operative period, long term } \\
\text { outcome not reported }\end{array}$ \\
\hline
\end{tabular}

years old - except for one who came for medical attention at the age of $21 .{ }^{3}$ Out of these 23 patients with PHPT who manifested either unilateral or bilateral genu valgum, 13 were females. The underlying reason for the occurrence of such deformity in this particular age group remains unclear. It has been postulated that the direct effect of elevated parathyroid hormone on the epiphyseal plate and bone remodeling during the pubertal growth spurt could be the main contributing factor. ${ }^{4}$

Primary hyperparathyroidism in children and adolescents is caused by either parathyroid adenoma (solitary or multiple) or hyperplasia, which may be sporadic or familial. Parathyroid carcinoma in this age group is rarely reported. ${ }^{2}$ Familial causes encompass MEN 1 or MEN 2A,
HPT-JT and FIHPT. Our patient most likely has sporadic PHPT due to the absence of a family history of the aforementioned disorders. Moreover, additional screening revealed a normal prolactin level and a normal pituitary gland on magnetic resonance imaging. Solitary parathyroid adenoma appears to be the etiology in all the reported cases, including our patient (Table 2).

Our patient presented with isolated bilateral genu valgum with no other symptoms attributable to hypercalcemia. This piece of information has to be taken with a pinch of salt because it is well-known that children and adolescents with PHPT may have vague and non-specific symptoms involving the gastrointestinal, renal, musculoskeletal and neurological systems. ${ }^{1,2}$ These non-specific complaints 
may potentially be dismissed as trivial and hence fail to raise the alarm unless a calcium level, which is often not part of routine blood tests in children, is checked. As a consequence, delayed diagnosis of PHPT and end-organ damage at presentation are common in this age group.

Interestingly, the lack of routine biochemical screening in children and adolescents may not exclusively justify the more severe presentations of PHPT in this juvenile population compared to their adult counterparts. This is because symptomatic PHPT remains uncommon at the fourth and fifth decades of life, as it is detected mainly by routine biochemical tests. ${ }^{1}$ The question of whether juvenile PHPT and adult PHPT represent two separate entities remains unanswered. A meta-analysis of 16 studies that included 268 juvenile and 2,405 adult patients with PHPT demonstrated that the former had greater hypercalcemia and hypercalciuria, despite similar serum iPTH levels. Decreased parathyroid adenoma sensitivity to negative feedback by calcium and increased target tissue responsiveness to the effects of parathyroid hormone in juvenile PHPT were suggested to be the key differences between these two age groups, providing the basis for future research. ${ }^{5}$

In addition to genu valgum, most patients reported in literature also manifested with other radiologic changes typical of primary hyperparathyroidism.,6-20 These include subperiosteal bone resorption especially over the phalanges, acro-osteolysis, subchondral resorption around specific joints, brown tumors, salt-and-pepper radiologic appearance of the skull and osteopenia. It is noteworthy that three patients were initially treated as vitamin $\mathrm{D}$ deficiency rickets before the final diagnosis of PHPT was made. ${ }^{20-22}$ In fact, genu valgum is one of the known clinical features of nutritional rickets. ${ }^{23}$ In these patients, the lack of clinical improvement and new onset of hypercalcemia coupled with persistent elevation of parathyroid hormone following vitamin D repletion eventually unveiled the diagnosis of PHPT. On a different note, concomitant nephrolithiasis seems infrequent, as only four out of twenty-three total cases in literature exhibited the said complication. ${ }^{4,9,17}$

Parathyroidectomy is the mainstay of treatment in children with PHPT. ${ }^{1}$ Treatment goals include immediate and permanent cure of excessive calcium and parathyroid hormone secretion, mitigation of symptoms as well as reversal of end-organ damage. ${ }^{2}$ All reported cases including ours underwent successful parathyroidectomy. Hungry bone syndrome during the immediate postoperative period, which constituted a significant risk in this age group due to the greater disease severity, was reported in a handful of cases.,19,20 Long-term outcomes postparathyroidectomy are favorable as evidenced by clinical and/or biochemical resolution in majority of patients. Our patient's calcium levels remained within normal range six months after surgery without any calcium or vitamin D supplement (Table 1). However, he will still require osteotomy to correct his bilateral genu valgum.
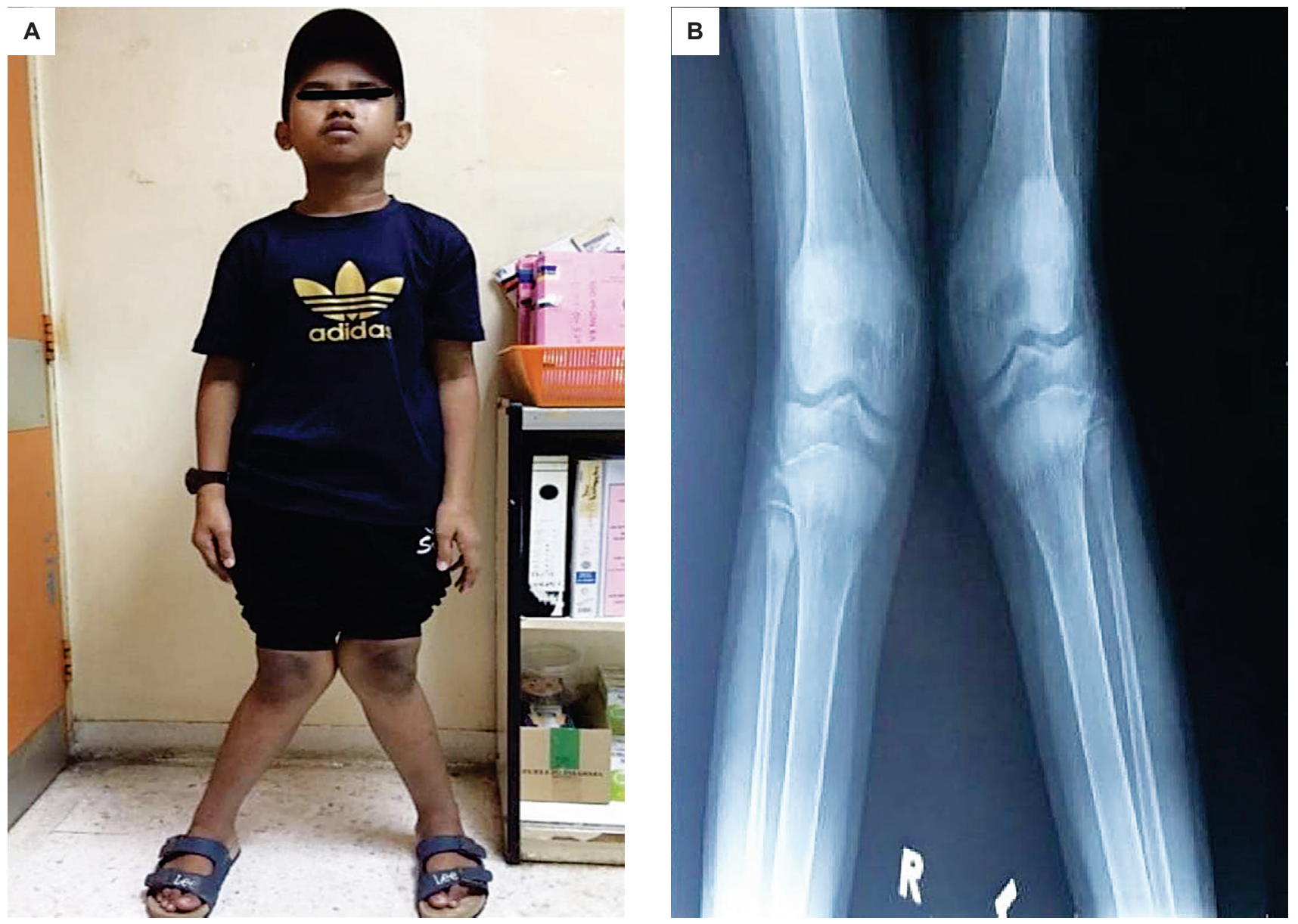

Figure 1. Clinical $(A)$ and radiologic $(B)$ evidence of bilateral genu valgum. 
In conclusion, primary hyperparathyroidism in children and adolescents is rare and often diagnosed late, with genu valgum being an unusual manifestation of this disorder. Nevertheless, a high index of suspicion is warranted, as prompt parathyroidectomy may lead to cure and reversal of debilitating complications.

\section{Acknowledgment}

The authors would like to thank the Director General of Health Malaysia for the permission to publish this case report.

\section{Ethical Consideration}

Patient consent was obtained before submission of the manuscript.

\section{Statement of Authorship}

All authors certified fulfillment of ICMJE authorship criteria.

\section{Author Disclosure}

All authors declared no conflicts of interest.

\section{Funding Source}

None.

\section{References}

1. Roizen J, Levine MA. Primary hyperparathyroidism in children and adolescents. J Chin Med Assoc. 2012;75(9):425-34. PMID: 22989537. PMCID: PMC3710287. https://doi.org/10.1016/j.jcma.2012.06.012.

2. Alagaratnam S, Kurzawinski TR. Aetiology, diagnosis and surgical treatment of primary hyperparathyroidism in children: New trends. Horm Res Paediatr. 2015. PMID: 25966652. https://doi.org/ $10.1159 / 000381622$

3. Balch HE, Spiegel EH, Upton AL, Kinsell LW. Hyperparathyroidism: Report of 2 cases with some relatively unusual manifestations. J Clin Endocrinol Metab. 1953;13(6):733-8. PMID: 13061594. https://doi.org/ 10.1210/jcem-13-6-733.

4. Rapaport D, Ziv Y, Rubin M, Huminer D, Dintsman M. Primary hyperparathyroidism in children. J Pediatr Surg. 1986;21(5):395-7. PMID: 3712190. https://doi.org/10.1016/s0022-3468(86)80505-x.

5. Roizen J, Levine MA. A meta-analysis comparing the biochemistry of primary hyperparathyroidism in youths to the biochemistry of primary hyperparathyroidism in adults. J Clin Endocrinol Metab. 2014;99(12):4555-64. PMID: 25181388. PMCID: PMC4255125. https:// doi.org/10.1210/jc.2014-2268

6. McClure RD, Lam CR. End-results in the treatment of hyperparathyroidism. Ann Surg. 1945;121(4):454-66. PMID: 17858584. PMCID: PMC1618130. https://doi.org/10.1097/00000658-19450400000006.

7. Lloyd HM, Aitken RE, Ferrier TM. Primary hyperparathyroidism resembling rickets of late onset. Brit Med J. 1965;2(5466):853-6. PMID: 5827800. PMCID: PMC1846345. https://doi.org/10.1136/bmj.2.5466.853.

8. Kauffmann C, Leroy B, Sinnassamy P, Carlioz H, Gruner M, Bensman A. [A rare cause of bone pain in children: Primary hyperparathyroidism caused by adenoma.] Arch Fr Pediatr. 1993;50(9):771-4 [Article in French]. PMID: 8060206.
9. Menon PS, Madhavi N, Mukhopadhyaya S, Padhy AK, Bal CS, Sharma LK. Primary hyperparathyroidism in a 14 year old girl presenting with bone deformities. J Paediatr Child Health. 1994;30(5):441-3. PMID: 7833084. https://doi.org/10.1111/j.1440-1754.1994.tb00698.x.

10. Harman CR, van Heerden JA, Farley DR, Grant CS, Thompson GB, Curlee K. Sporadic primary hyperparathyroidism in young patients: A separate entity? Arch Surg. 1999;134(6): 651-5. PMID: 10367876 https://doi.org/10.1001/archsurg.134.6.651.

11. Walczyk A, Szalecki M, Kowalska A. Primary hyperparathyroidism: A rare endocrinopathy in children. Two case reports. Endokrynol Pol. 2011;62(4):346-50. PMID: 21879476.

12. Ratnasingam J, Tan ATB, Vethakkan SR, et al. Primary hyperparathyroidism: A rare cause of genu valgus in adolescence. J Clin Endocrinol Metab. 2013;98(3):869-70. PMID: 23337722 https://doi.org/10.1210/jc.2012-3839.

13. Ramkumar S, Kandasamy D, Vijay MK, Tripathi M, Jyotsna VP. Genu valgum and primary hyperparathyroidism in children. Int J Case Rep Images. 2014;5(6):401-7. https://doi:10.5348/ijcri-201455-CS-10041.

14. Sharma S, Kumar S. Bilateral genu valgum: An unusual presentation of juvenile primary hyperparathyroidism. Oxf Med Case Reports. 2016;2016(7):141-3. PMID: 27471596. PMCID: PMC4962889. https://doi. org/10.1093/omcr/omw023.

15. Zil-E-Ali A, Latif A, Rashid A, Malik A, Khan HA. Presentation of parathyroid adenoma with genu valgum and thoracic deformities J Pak Med Assoc. 2016;66(1):101-3. PMID: 26712192.

16. Arambewela MH, Liyanarachchi KD, Somasundaram NP, Pallewatte AS, Punchihewa GL. Case report: Rare skeletal manifestations in a child with primary hyperparathyroidism. BMC Endocr Disord. 2017;17(1):45. PMID: 28732535. PMCID: PMC5521059. https://doi. org/10.1186/s12902-017-0197-z.

17. Kamath SP, Shenoy J, Kini KP, Shetty KB, Pai KA. Primary hyperparathyroidism presenting as bilateral genu valgum. Int J Health Allied Sci. 2018;7(2):114-6. https://doi.org/10.4103/ijhas.IJHAS_69_1.

18. Paruk IM, Pirie FJ, Motala AA. Rickets mimicker: A report of two cases of primary hyperparathyroidism in adolescence. J Endocrinol Metab Diabetes S Afr. 2019; 24(1):23-7. https://doi.org/10.1080/16089677. 2018.1546365.

19. Rao KS, Agarwal P, Reddy J. Parathyroid adenoma presenting as genu valgum in a child: A rare case report. Int J Surg Case Rep. 2019;59:2730. PMID: 31102836. PMCID: PMC6525286. https://doi.org/10.1016/ j.ijscr.2019.03.063.

20. Yanrismet $Y$, Tridjaja B. Genu valgum as a rare clinical manifestation in child with primary hyperparathyroidism: A case report. Arch Dis Child. 2019;104(Suppl 3):A276. https://doi.org/10.1136/archdischild2019-epa.646.

21. Dutta D, Kumar M, Das RN, et al. Primary hyperparathyroidism masquerading as rickets: Diagnostic challenge and treatment outcomes. J Clin Res Pediatr Endocrinol. 2013;5(4):266-9. PMID 24379038. PMCID: PMC3890227. https://doi.org/10.4274/Jcrpe.1060.

22. Khan KA, Qureshi SU. Primary hyperparathyroidism masquerading as rickets. J Coll Physicians Surg Pak. 2019;29(9):891-4. PMID: 31455490. https://doi.org/10.29271/jcpsp.2019.09.891.

23. Misra M, Pacaud D, Petryk A, Collett-Solberg PF, Kappy M, Drug and Therapeutics Committee of the Lawson Wilkins Pediatric Endocrine Society. Vitamin D deficiency in children and its management: Review of current knowledge and recommendations. Pediatrics. 2008;122(2):398-417. PMID: 18676559. https://doi.org/10.1542/peds. 2007-1894.

Authors are required to accomplish, sign and submit scanned copies of the JAFES Author Form consisting of: (1) Authorship Certification, that authors contributed substantially to the work, that the manuscript has been read and approved by all authors, and that the requirements for authorship have been met by each author; (2) the Author Declaration, that the article represents original material that is not being considered for publication or has not been published or accepted for publication elsewhere, that the article does not infringe or violate any copyrights or intellectual property rights, and that no references have been made to predatory/ suspected predatory journals; (3) the Author Contribution Disclosure, which lists the specific contributions of authors; and (4) the Author Publishing Agreement which retains author copyright, grants publishing and distribution rights to JAFES, and allows JAFES to apply and enforce an Attribution-Non-Commercial Creative Commons user license. Authors are also required to accomplish, sign, and submit the signed ICMJE form for Disclosure of Potential Conflicts of Interest. For original articles, authors are required to submit a scanned copy of the Ethics Review Approval of their research as well as registration in trial registries as appropriate. For manuscripts reporting data from studies involving animals, authors are required to submit a scanned copy of the Institutional Animal Care and Use Committee approval. For Case Reports or Series, and Images in Endocrinology, consent forms, are required for the publication of information about patients; otherwise, appropriate ethical clearance has been obtained from the institutional review board. Articles and any other material published in the JAFES represent the work of the author(s) and should not be construed to reflect the opinions of the Editors or the Publisher. 